\title{
Thermodynamic Analysis of the Ca-C-N System
}

\author{
C. A. Pickles' and J. M. Toguri' (posthumously) \\ 'Department of Mining Engineering, Queen's University \\ Kingston, Ontario, Canada, K7L 3N6 \\ ${ }^{2}$ Department of Materials Science and Engineering \\ University of Toronto, Toronto, Ontario, Canada, MSS $3 E 4$
}

(Received May 17, 2004;final form May 28, 2004)

\begin{abstract}
In the calcium-carbon-nitrogen (Ca-C-N) system there are two known ternary compounds: calcium cyanamide $\left(\mathrm{CaCN}_{2}\right)$ and calcium cyanide $\left(\mathrm{Ca}(\mathrm{CN})_{2}\right)$. Calcium cyanamide is commercially produced by the nitrogenation of calcium carbide, while calcium cyanide is manufactured by the reaction of calcium cyanamide with carbon in a fused salt melt. In addition to the industrial production of these compounds, it has also been proposed that they can act as intermediate species in natural diamond formation.

There is very little information in the literature regarding the thermodynamic properties of the $\mathrm{Ca}-\mathrm{C}-\mathrm{N}$ system and in particular calcium cyanide. Since this compound apparently only forms as a complex in a molten salt under very specific conditions, then it has proven difficult to determine its thermodynamic properties. Previously, the authors have determined these properties and in the present research, this thermodynamic information was utilized to develop predominance area diagrams for the $\mathrm{Ca}-\mathrm{C}-\mathrm{N}$ system at various temperatures. The application of this thermodynamic information leads to an improved understanding of the mechanism of formation of calcium cyanide and also the factors which govern the optimization of the industrial production method.
\end{abstract}

\section{INTRODUCTION}

Calcium cyanamide is commercially produced via a gas-solid reaction between nitrogen gas and calcium carbide $\left(\mathrm{CaC}_{2}\right)$. It is employed either as a fertilizer or as a reagent in iron and steel production. Also it can be converted into calcium cyanide or "black cyanide" by a process which was originally developed by Landis and involves the reaction of calcium cyanamide with carbon in the presence of a fused salt, such as sodium chloride, at temperatures in the range of $1200^{\circ} \mathrm{C}$ to $1400^{\circ} \mathrm{C} / 1-3 /$. Calcium cyanide is mainly utilized as a reagent in the leaching processes for the extraction of some precious metals, in particular, for the recovery of gold. In the industrial manufacture of calcium cyanide, from calcium cyanamide, the conversion efficiency is only about ninety to ninety-five percent and also there is considerable dilution by impurities. Therefore, the cyanide product contains on average only about fortyeight to fifty percent active cyanide, with the remainder being essentially inert material in the leaching process. Thus, commercial "black cyanide" has a serious economic disadvantage with regard to shipping costs, as compared to sodium cyanide, which is essentially pure (98\%) and contains up to fifty-two percent active cyanide. In addition to the importance of calcium cyanamide and calcium cyanide as industrial products it has also been proposed that these species act as intermediate compounds in natural diamond formation in kimberlite pipes $/ 4,5 /$.

In this paper, the commercial production processes for calcium cyanamide and calcium cyanide are reviewed. The authors have previously determined the thermodynamic properties and the standard free energy of formation of calcium cyanide $\left(\Delta \mathrm{G}^{0} \mathrm{f}\right) / 6 /$. These are employed both to develop predominance area diagrams for the $\mathrm{Ca}-\mathrm{C}-\mathrm{N}$ system at various temperatures and also 
to explain the potential possible reaction paths to produce calcium cyanide. Subsequently, a possible reaction mechanism for the formation of calcium cyanide in the commercial production process is proposed. The thermodynamic information and the reaction mechanism are utilized to explain the industrial results. Also some comments are made regarding the possible roles played by calcium cyanamide and calcium cyanide compounds in natural diamond formation.

\section{CALCIUM CYANAMIDE AND CALCIUM CYANIDE PRODUCTION}

Since calcium cyanamide is an intermediate compound in the manufacture of calcium cyanide then the production of these two compounds will be discussed sequentially. The actual industrial production of calcium cyanide involves three major steps. Firstly, calcium carbide $\left(\mathrm{CaC}_{2}\right)$ is produced by reacting lime and carbon at temperatures over $1800^{\circ} \mathrm{C}$ according to the following reaction:

$$
3 \mathrm{C}+\mathrm{CaO}=\mathrm{CaC}_{2}+\mathrm{CO}
$$

The coke and lime are premixed and fed into an electric arc furnace. Fine material, which can amount to about fifteen percent of the charge, can be injected through the electrodes. Reaction (1) is reversible and thus the molten $\mathrm{CaC}_{2}$, which is tapped from the furnace at about $1800^{\circ} \mathrm{C}$, is rapidly cooled by casting the liquid carbide into heavy steel moulds. The cooled product is ground in ball mills under a nitrogen atmosphere to minimize oxidation. The carbide product contains about eighty percent calcium carbide with the balance being lime and unreacted coke. The carbide which is not used for the production of "black cyanide" can be sold to steel plants as a desulphurizing reagent for molten pig iron or as the raw material for the manufacture of acetylene.

In the second step, the ground calcium carbide $\left(\mathrm{CaC}_{2}\right)$ is converted into calcium cyanamide $\left(\mathrm{CaCN}_{2}\right)$ according to the following reaction:

$$
\mathrm{CaC}_{2}+\mathrm{N}_{2}=\mathrm{CaCN}_{2}+2 \mathrm{C}
$$

About one mass percent calcium fluoride $\left(\mathrm{CaF}_{2}\right)$ is mixed with the charge and the fluoride acts as a flux and/or catalyst. Since reaction (2) is a gas-solid reaction and relatively slow, then it is necessary to design the reactor such that the contact between the nitrogen gas and the solid calcium carbide is promoted. The reaction vessel is a refractory lined truncated cone with the wide side up. The reaction temperature is controlled between $1050^{\circ} \mathrm{C}$ and $1140^{\circ} \mathrm{C}$ and the reaction time is about five days. As shown by equation (2), carbon is also produced as a result of the reaction and remains entrapped in the cyanamide. The product contains about $70 \%$ calcium cyanamide, $12 \%$ free lime, $12 \%$ free graphite and $0.5 \%$ unreacted calcium carbide. The material is crushed and can be sold as a fertilizer or as an agent for removing titanium from steel or it can be converted into "black cyanide".

Calcium cyanide is produced by the reaction of the calcium cyanamide $\left(\mathrm{CaCN}_{2}\right)$ with carbon, sodium chloride and calcium carbide in a smothered arc furnace at temperatures between $1200^{\circ} \mathrm{C}$ to $1400^{\circ} \mathrm{C}$ according to the following reaction:

$$
\mathrm{CaCN}_{2}+\mathrm{C}=\mathrm{Ca}(\mathrm{CN})_{2}
$$

The residence time of the material in the furnace is about twenty minutes and carbon is used as the furnace refractory. The amount of free carbon in the cyanamide is more than the stoichiometric requirement as given by reaction (3). The mass ratio of $\mathrm{NaCl}$ to $\mathrm{CaCN}_{2}$ is usually in the range of 0.55 to 0.60 while the $\mathrm{CaC}_{2}$ to $\mathrm{NaCl}$ mass ratio is about 0.08 . The reaction occurs readily in the fused salt mixture, however, it is highly reversible and the product must be quenched. Therefore, the liquid cyanide is rapidly cooled on a water-cooled drum and the cyanide is obtained in the form of thin black flakes, which are typically 1 to $2 \mathrm{~mm}$ in thickness. A representative analysis of the cyanide is as follows: 45 $48 \% \mathrm{Ca}(\mathrm{CN})_{2}, 31.9 \% \mathrm{NaCl}, 11.8 \% \mathrm{CaO}, 2.8 \% \mathrm{C}, 2.8 \%$ $\mathrm{CaCN}_{2}, 2.0 \% \mathrm{Al}_{2} \mathrm{O}_{3}$ and $\mathrm{Fe}_{2} \mathrm{O}_{3}, 1.2 \% \mathrm{CaCl}_{2}, 0.9 \% \mathrm{SiO}_{2}$, $0.9 \% \mathrm{CaS}, 0.5 \% \mathrm{CaF}_{2}$ and $1.6 \% \mathrm{CaC}_{2}$. The major impurities are seen to be salt, lime, carbon and calcium cyanamide. The equivalent sodium cyanide concentration of the product is in the range of forty eight to fifty percent. 


\section{PREDOMINANCE AREA DIAGRAMS OF THE Ca-C-N SYSTEM}

The calcium-carbon-nitrogen system consists of the following possible species: $\mathrm{Ca}, \mathrm{Ca}_{3} \mathrm{~N}_{2}, \mathrm{CaC}_{2}, \mathrm{CaCN}_{2}$ and $\mathrm{Ca}(\mathrm{CN})_{2}$. The thermodynamic properties of these species are well-known except for calcium cyanide. In a previous study, the authors estimated the standard entropy $\left(S^{\circ}{ }_{298}\right)$ and the heat capacity $\left(C_{p}\right)$ of calcium cyanide and these are given in Table $1 / 6 /$. The standard enthalpy $\left(\mathrm{H}^{\circ}{ }_{298}\right)$ for calcium cyanide, which was utilized in the calculations, was that given by Parker et al. 171 . Also included in Table $I$ are the more recent thermodynamic properties of calcium cyanamide, which were taken from the literature $/ 8 /$ and utilized in the present calculations. The values for calcium cyanamide and calcium cyanide were used to calculate the standard free energy of formation of calcium cyanide from the elements from which the standard free energy of reaction (3) could be calculated as follows:

$$
\begin{aligned}
\Delta G^{\circ}= & 174.1-0.1248 \mathrm{~T}(\mathrm{~kJ} / \mathrm{mole}) \\
& 1400 \mathrm{~K}<\mathrm{T}<1600 \mathrm{~K}
\end{aligned}
$$

The estimated standard free energies of formation of calcium cyanide from calcium cyanamide and carbon as a function of temperature are shown in Figure 1.

Using the thermodynamic properties of calcium

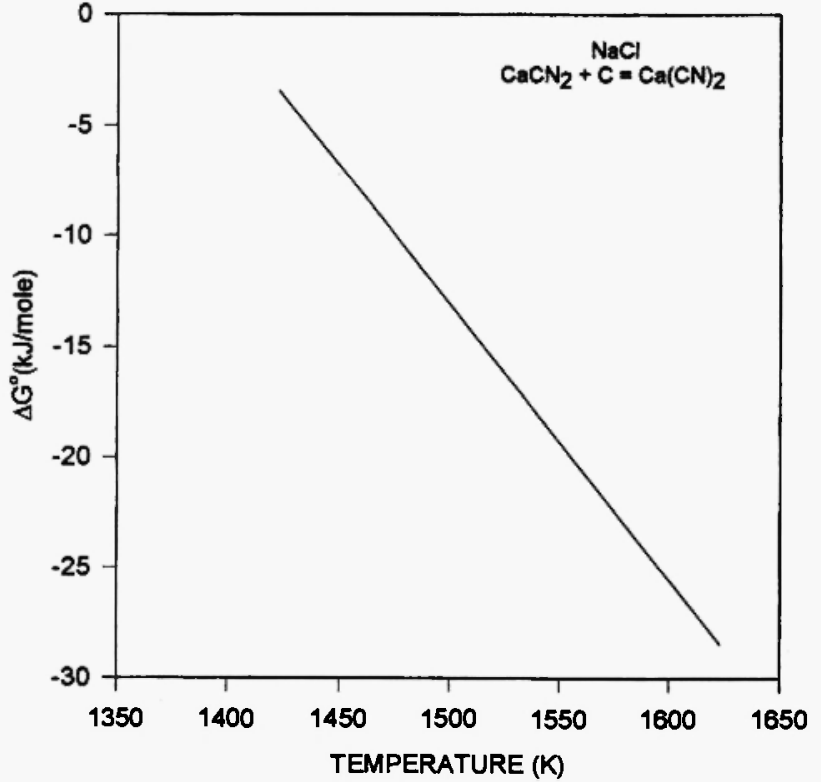

Fig. 1: Estimated values for the standard free energy of formation of calcium cyanide from calcium cyanamide and carbon as a function of temperature.

cyanide it is possible to develop predominance area diagrams for the $\mathrm{Ca}-\mathrm{C}-\mathrm{N}$ system. A three dimensional plot of the diagram is shown in Figure 2, where one axis is temperature, which varies from $1473 \mathrm{~K}$ to $1673 \mathrm{~K}$, and the other two axes are $\log {\mathrm{P}_{\mathrm{N}_{2}}}_{\text {and }} \log \mathrm{a}_{\mathrm{g}}$. Here the

Table 1

Thermodynamic properties for calcium cyanamide and calcium cyanide that were utilized in the calculations.

The values for $\mathrm{Ca}(\mathrm{CN})_{2}$ are estimations /6/ except for $\mathrm{H}^{\circ}{ }_{298}$ which is from reference $/ 7 /$.

\begin{tabular}{|c|c|c|c|c|c|c|}
\hline \multirow[t]{2}{*}{ Substance } & \multirow{2}{*}{$\begin{array}{c}\mathrm{H}^{\mathrm{o}}{ }_{298} \\
(\mathrm{~kJ} / \mathrm{mole}) \\
\end{array}$} & \multirow{2}{*}{$\begin{array}{c}\mathrm{S}_{298}^{\circ} \\
(\mathrm{kJ} / \mathrm{mole})\end{array}$} & \multicolumn{2}{|c|}{$\begin{array}{c}\mathrm{C}_{\mathrm{p}} \\
(\mathrm{J} / \text { mole } \mathrm{K})\end{array}$} & \multirow{2}{*}{$\begin{array}{c}\text { Temperature range } \\
(\mathrm{K})\end{array}$} & \multirow{2}{*}{$\begin{array}{c}\mathrm{H}_{\mathrm{f}} \\
(\mathrm{kJ} / \text { mole }) \\
\end{array}$} \\
\hline & & & A & B & & \\
\hline $\mathrm{CaCN}_{2}(\mathrm{~s})$ & -350.62 & 81.59 & 91.84 & 18.21 & 298 to 1700 & - \\
\hline $\mathrm{Ca}(\mathrm{CN})_{2}(\mathrm{~s})$ & -184.52 & 201.77 & 107.49 & 0.788 & 298 to 913 & 12.92 \\
\hline $\mathrm{Ca}(\mathrm{CN})_{2}(1)$ & - & - & 127.62 & - & 913 to 1700 & - \\
\hline
\end{tabular}

The values for $\mathrm{CaCN}_{2}$ are from reference $/ 8$. 


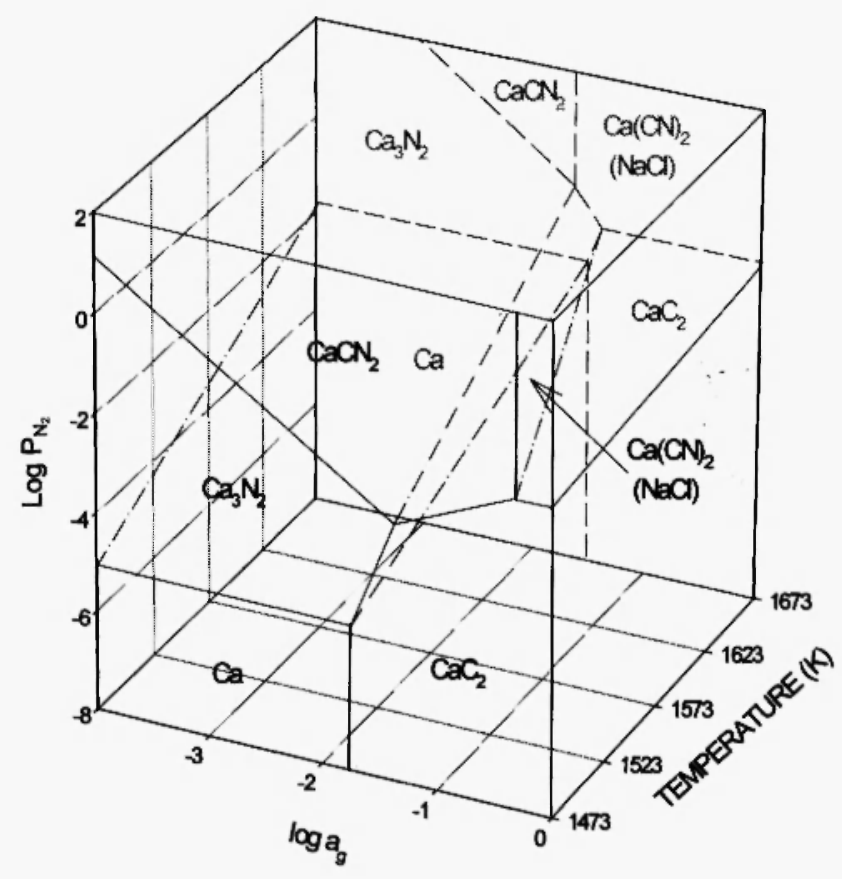

Fig. 2: Three dimensional plot of the predominance area diagram for the calcium-carbon-nitrogen system.

carbon is assumed to be in the form of graphite. At 1473 $\mathrm{K}$, the phase field for calcium cyanide is small but the compound is stable at carbon saturation $\left(a_{k}=1\right)$ and pressures of nitrogen approaching one atmosphere. As the temperature increases, calcium cyanide becomes more stable and therefore the phase field for calcium cyanide increases in size. Also a new equilibrium line develops between calcium nitride and calcium cyanide. Since nitrogen gas is not involved as a reagent in the conversion of calcium cyanamide to calcium cyanide, then the equilibrium line between these two phases is independent of the nitrogen pressure.

Isothermal slices of the $\mathrm{Ca}-\mathrm{C}-\mathrm{N}$ system are shown in Figure 3(a) to (f) for temperatures from $1373 \mathrm{~K}$ to 1873 $\mathrm{K}$ with $\log \mathrm{a}_{\mathrm{g}}$ as the abscissa and $\log \mathrm{P}_{\mathrm{N}_{2}}$ as the ordinate.

Here again the carbon is in the form of graphite. At $1373 \mathrm{~K}$, calcium cyanide is not stable and therefore does not appear on the diagram as shown in Figure 3(a). Calcium cyanamide is stable at high pressures of nitrogen and high carbon activities, while calcium carbide is stable at low pressures of nitrogen and high carbon activities. As shown in Figure 3(b), calcium cyanide is stable at $1473 \mathrm{~K}$ at both high nitrogen pressures and activities of carbon. The diagram indicates that thermodynamically it should be possible to produce calcium cyanide from calcium cyanamide by increasing the carbon activity and also from calcium carbide by increasing the nitrogen pressure. However, at this temperature it is not possible to produce calcium cyanide directly from either calcium nitride or calcium metal. As the temperature increases to $1573 \mathrm{~K}$ and 1673 $\mathrm{K}$, as shown in Figure 3(c) and (d) respectively, calcium cyanide becomes more stable at lower activities of carbon and therefore the relative size of the phase stability region of calcium cyanide increases. It can also be noted that the minimum nitrogen pressure required for calcium cyanide formation increases slightly with increasing temperature. At $1773 \mathrm{~K}$, as shown in Figure 3(e), a new equilibrium line is observed between calcium nitride and calcium cyanide and thus it should be possible to directly convert calcium nitride to calcium cyanide. This line increases in length at higher temperatures as shown in Figure 3(f). It should be noted that in the above calculations and predominance area diagrams, the calcium cyanide is dissolved in molten sodium chloride and the boiling points and the formation of various gaseous species are not accounted for.

\section{CALCIUM CYANIDE FORMATION}

\section{Proposed Reactions for Calcium Cyanide Formation}

The production of calcium cyanide is a complex process and the actual reactions have not been identified. However, a number of different reaction mechanisms have been proposed to describe the black cyanide process. One possible approach to understanding the process is to consider the role of the sodium chloride which could serve one or more of the following functions: (1) act as a flux to provide a medium for the ionic reactions, (2) catalyze the reaction and (3) participate in the reaction. If the salt is only considered to act as a flux and does not participate in the reaction then the process can be described in a 
$1373 \mathrm{~K}$

(a)

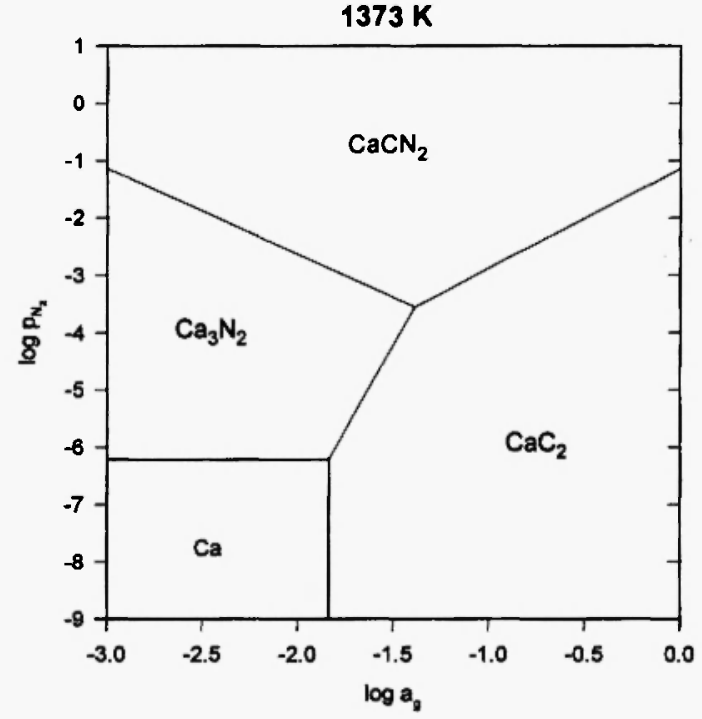

(c)

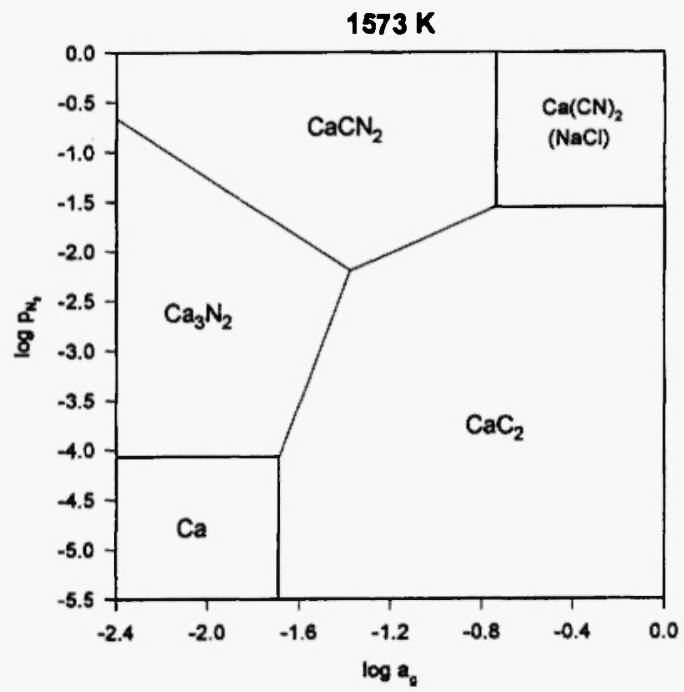

(e)

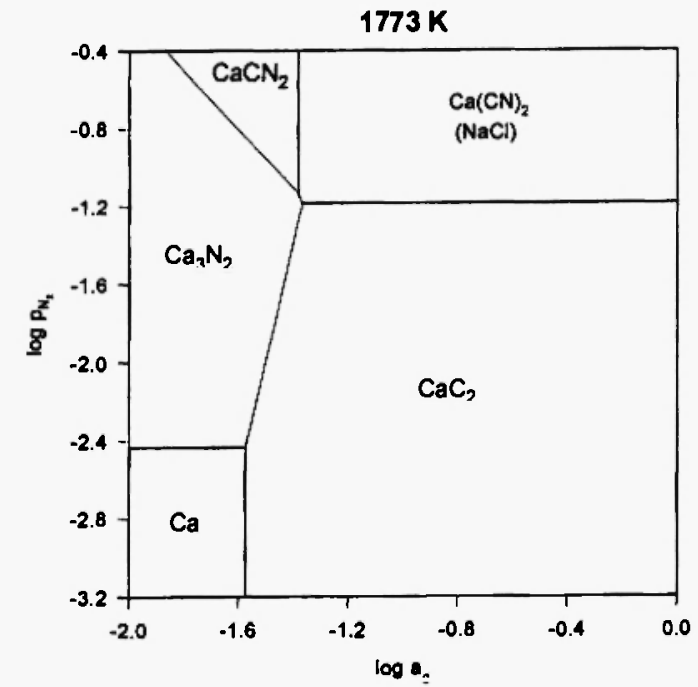

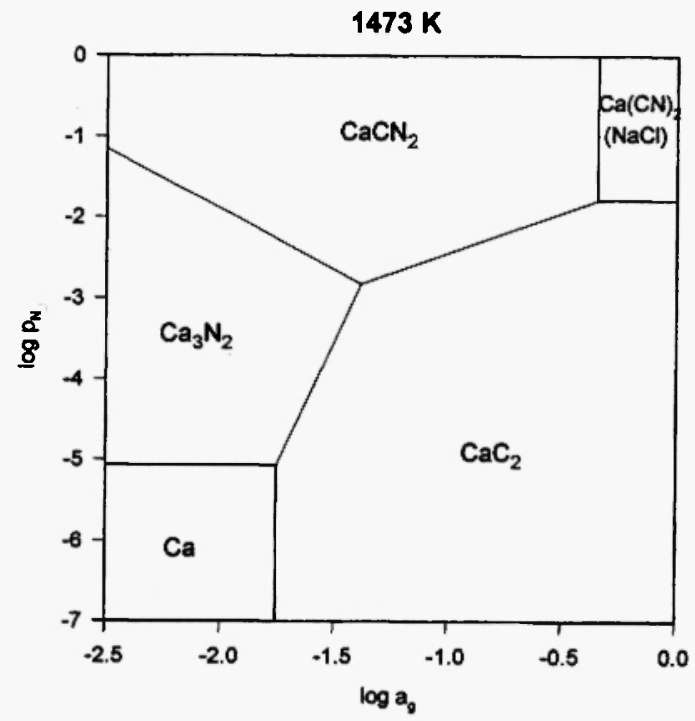

(b)

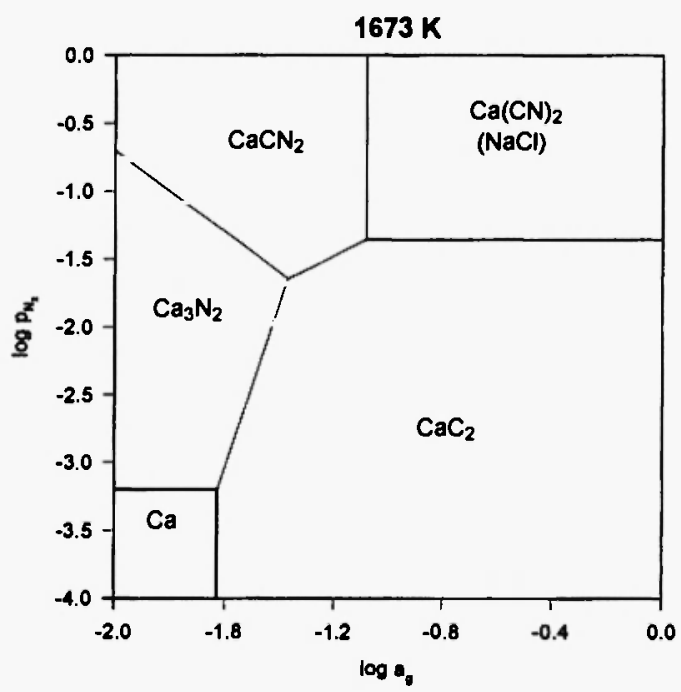

(d)

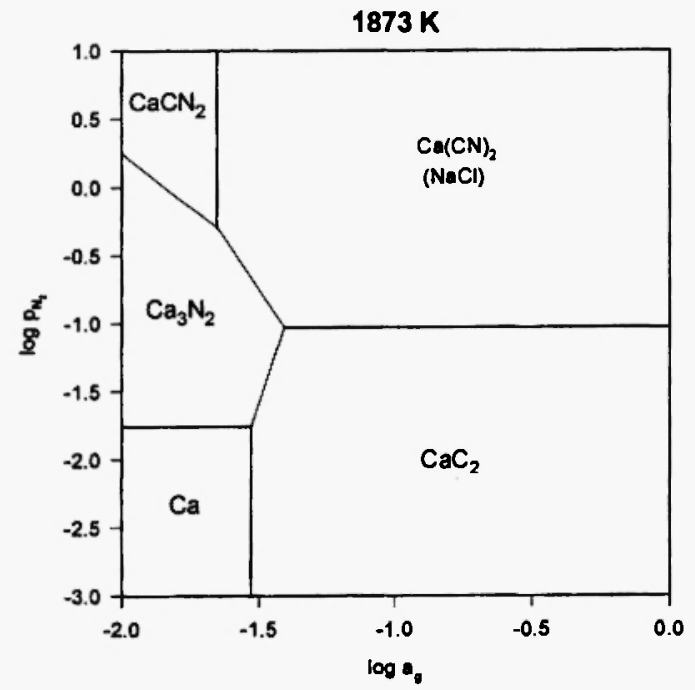

(f)

Fig. 3: Predominance area diagrams for the calcium-carbon-nitrogen system at various temperatures; (a) $1373 \mathrm{~K}$, (b) $1473 \mathrm{~K}$, (c) $1573 \mathrm{~K}$, (d) $1673 \mathrm{~K}$, (e) $1773 \mathrm{~K}$, (f) $1873 \mathrm{~K}$. 
manner similar to equation (3) as follows:

$$
\mathrm{CaCN}_{2}+\mathrm{C}=\mathrm{CaCl}(\mathrm{CN})_{2}
$$

On the other hand, if the salt is assumed to participate in the process then a series of reactions can be written with increasing amount of carbon as a reagent:

$$
\begin{aligned}
& \mathrm{CaCN}_{2}+2 \mathrm{NaCl}+\mathrm{C}=2 \mathrm{NaCN}+\mathrm{CaCl}_{2} \\
& 2 \mathrm{CaCN}_{2}+2 \mathrm{NaCl}+2 \mathrm{C} \\
& \quad=\mathrm{Ca}(\mathrm{CN})_{2}+2 \mathrm{NaCN}+\mathrm{CaCl}_{2}
\end{aligned}
$$

or in more general terms:

$$
\begin{aligned}
x \mathrm{CaCN}_{2} & +2 \mathrm{NaCl}+x \mathrm{CC}=(\mathrm{x}-\mathrm{I}) \mathrm{Ca}(\mathrm{CN})_{2} \\
& +2 \mathrm{NaCN}+\mathrm{CaCl}_{2}
\end{aligned}
$$

where $\mathrm{x}$ is the number of moles of calcium cyanamide added as a reagant. At $x=1$ no calcium cyanide is formed and reaction (7) becomes equivalent to reaction (5). For values of $x>1$, the equation can be balanced independently of the amount of sodium chloride since $x$ moles of calcium cyanamide react with $x$ moles of carbon to form $(x-1)$ moles of calcium cyanide. Figure 4 shows the standard free energy change for reaction (7) as a function of temperature for various $x$ values from 2 to 20. It can be seen that the lines all pivot around a single point $\left(1395 \mathrm{~K}\right.$ and $\left.\Delta \mathrm{G}^{\circ}=41 \mathrm{~kJ} / \mathrm{mole}\right)$ and

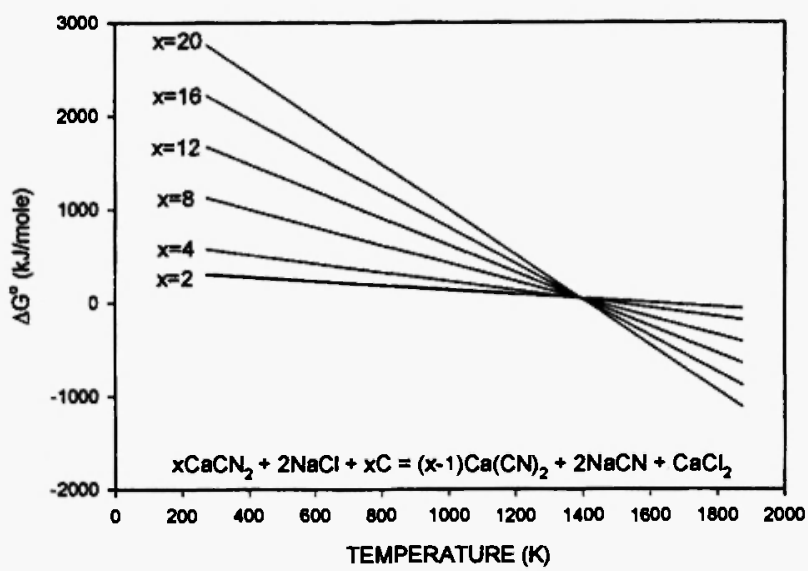

Fig. 4: Standard free energy changes for the reaction of calcium cyanamide, sodium chloride and carbon at various $\mathrm{x}$ values. become steeper with increasing value of $x$. The increasing slope indicates that for temperatures below the pivot point, the decomposition of calcium cyanide becomes more favorable with increasing values of $x$. On the other hand, at temperatures above the pivot point the formation of calcium cyanide becomes more favorable with increasing $x$. The temperature at which the standard free energy change for reaction (7) becomes equal to zero, is reduced as the $x$ value increases and therefore as the salt to cyanamide ratio decreases.

As shown in equations (5), (6) and (7) above, the inclusion of sodium chloride as a reagent in the process results in the formation of some sodium cyanide and calcium chloride in the products. In order to explain the presence of calcium chloride and sodium cyanide in the product, Petersen and Franck proposed that the following metathetical reaction occurred (9):

$$
\mathrm{Ca}(\mathrm{CN})_{2}+2 \mathrm{NaCl}=\mathrm{CaCl}_{2}+2 \mathrm{NaCN}
$$

Figure 5 shows the standard free energy change for this reaction as a function of temperature over the temperature range of interest. The values are large, positive and become more positive with increasing temperature and thus it is unlikely that this reaction occurs to any great extent.

Another possible approach to describing the "black cyanide" process would be to consider that again calcium cyanamide, salt and carbon are the reagents as shown in reactions (5-7) but also include lime as a

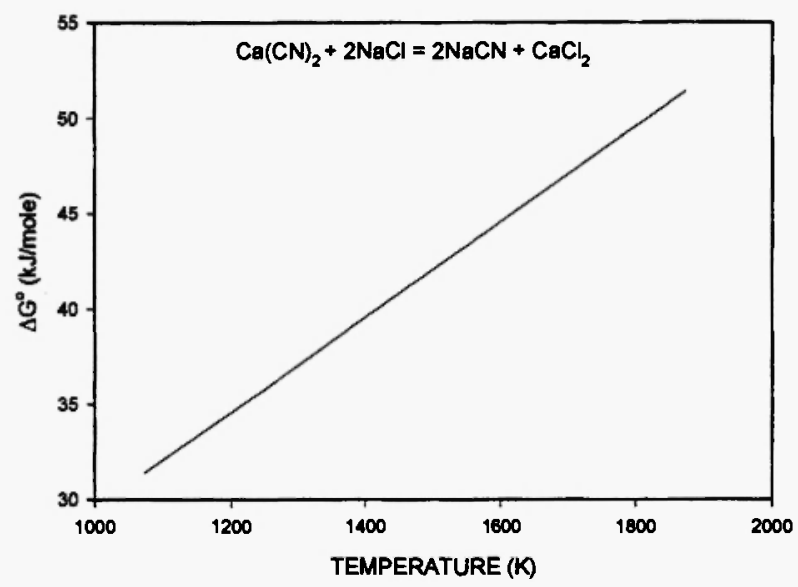

Fig. 5: Standard free energy changes for the metathetical reaction. 
reagent as follows:

$$
\begin{aligned}
\mathrm{CaO} & +2 \mathrm{CaCN}_{2}+2 \mathrm{NaCl}+5 \mathrm{C}=\mathrm{Ca}(\mathrm{CN})_{2} \\
& +2 \mathrm{NaCN}+\mathrm{CaCl}_{2}+\mathrm{CaC}_{2}+\mathrm{CO}(\mathrm{g})
\end{aligned}
$$

or in more general terms:

$$
\begin{aligned}
& \mathrm{CaO}+(1+x) \mathrm{CaCN}_{2}+2 \mathrm{NaCl}+(\mathrm{x}+4) \mathrm{C}= \\
& \quad \mathrm{Ca}(\mathrm{CN})_{2}+2 \mathrm{NaCN}+\mathrm{CaCl}_{2}+\mathrm{CaC}_{2}+\mathrm{CO}(\mathrm{g})
\end{aligned}
$$

Again for this reaction, the standard free energy change can be plotted as a function of temperature for $x$ values from 2 to 20 as shown in Figure 6 . In a manner similar to that described for reaction (7), a pivot point occurs at $1395 \mathrm{~K}\left(\Delta \mathrm{G}^{\mathrm{o}}=200 \mathrm{~kJ} / \mathrm{mole}\right)$ and the -omperature at which the free energy change for reaction (10) is zero decreases with increasing $x$ value and thereiore decreasing salt to cyanamide ratio. A comparison of the reaction with lime (Figure 6) to that without lime (Figure 4) shows that the reaction with lime is not as favorable.

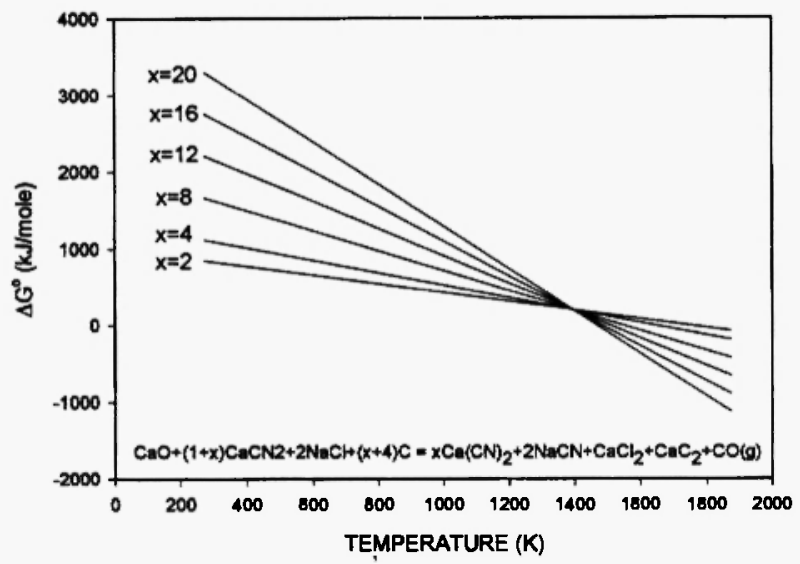

Fig. 6: Standard free energy changes for the reaction of calcium cyanamide, lime and carbon at various $x$ values.

A further variation resulting from the inclusion of lime as a reagent would involve the decomposition of some calcium cyanamide and the evolution of some nitrogen gas as follows:

$$
\begin{aligned}
\mathrm{CaO} & +3 \mathrm{CaCN}_{2}+2 \mathrm{NaCl}+6 \mathrm{C}=\mathrm{Ca}(\mathrm{CN})_{2} \\
& +2 \mathrm{NaCN}+\mathrm{CaCl}_{2}+2 \mathrm{CaC}_{2}+\mathrm{CO}+\mathrm{N}_{2}
\end{aligned}
$$

or in more general terms:

$$
\begin{gathered}
\mathrm{CaO}+(\mathrm{I}+\mathrm{x}) \mathrm{CaCN}_{2}+2 \mathrm{NaCl}+(\mathrm{x}+4) \mathrm{C}= \\
\quad(x-2) \mathrm{Ca}(\mathrm{CN})_{2}+2 \mathrm{NaCN}+\mathrm{CaCl}_{2} \\
+2 \mathrm{CaC}_{2}+\mathrm{CO}+\mathrm{N}_{2}
\end{gathered}
$$

Once again a plot of the standard free energy change for the reaction as a function of temperature as shown in Figure 7, at various $x$ values, gives a pivot point at 1395 $\mathrm{K}\left(\Delta \mathrm{G}^{\circ}=255 \mathrm{~kJ} / \mathrm{mole}\right)$ and the temperature at which the standard free energy change is zero decreases with increasing $x$ value and decreasing salt to cyanamide ratio. A comparison of the reaction with nitrogen gas evolution (Figure 7) to that without (Figure 6) shows that the reaction without is more favorable.

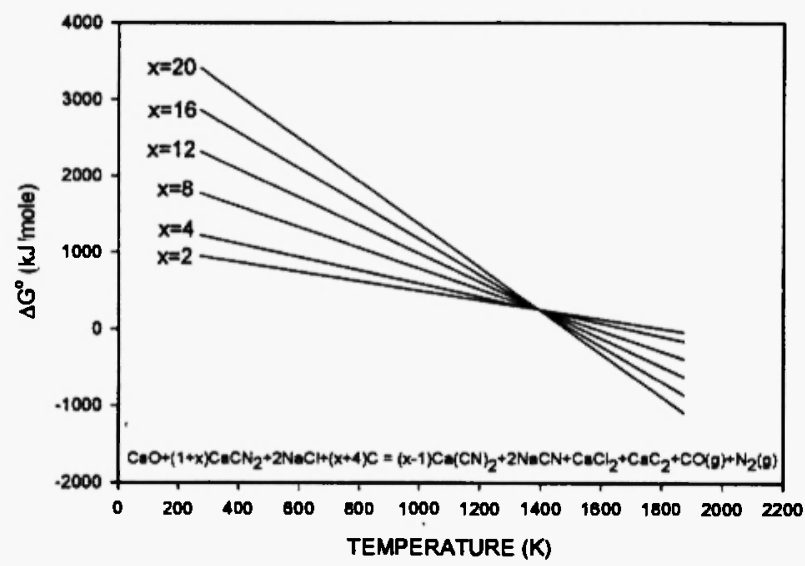

Fig. 7: Standard free energy changes for the reaction of calcium cyanamide, lime, sodium chloride and carbon at various $x$ values.

An alternative method to depict the "black cyanide" process is to consider that, as a result of the quenching process, the composition of the quenched "black cyanide" is equivalent to the melt composition at $1300^{\circ} \mathrm{C}$. After reaction and at $1300^{\circ} \mathrm{C}$ all of the species would be in equilibrium as dissolved species in the melt in ionic form. The major components would be: $\mathrm{Ca}(\mathrm{CN})_{2}, \mathrm{NaCl}, \mathrm{CaO}$, and $\mathrm{C}$ with smaller amounts of $\mathrm{NaCN}, \mathrm{CaC}_{2}, \mathrm{CaCl}_{2}$, and $\mathrm{CaCN}_{2}$. In order to describe the equilibrium, lime and carbon can be added to the left hand side of the metathetical reaction, i.e. reaction (8). Then in order to balance the equation, calcium carbide, calcium cyanamide and carbon monoxide are added to 
the right hand side as follows:

$$
\begin{aligned}
& \mathrm{CaO}+2 \mathrm{Ca}(\mathrm{CN})_{2}+2 \mathrm{NaCl}+2 \mathrm{C}= \\
& 2 \mathrm{NaCN}+\mathrm{CaCl}_{2}+\mathrm{CaCN}_{2}+\mathrm{CaC}_{2}+\mathrm{CO}
\end{aligned}
$$

or in more general terms:

$$
\begin{gathered}
(1+x) \mathrm{CaO}+(2+2 \mathrm{x}) \mathrm{Ca}(\mathrm{CN})_{2}+(2+\mathrm{x}) \mathrm{NaCl}+(2+1.5 \mathrm{x}) \mathrm{C}= \\
(2+\mathrm{x}) \mathrm{NaCN}+(1+0.5 \mathrm{x}) \mathrm{CaCl}_{2}+(1+1.5 \mathrm{x}) \mathrm{CaCN}_{2}+ \\
(1+\mathrm{x}) \mathrm{CaC}_{2}+(1+\mathrm{x}) \mathrm{CO}
\end{gathered}
$$

If some of the calcium cyanamide dissociates then some nitrogen gas will be produced and more calcium carbide will form:

$$
\begin{aligned}
2 \mathrm{CaO} & +4 \mathrm{Ca}(\mathrm{CN})_{2}+3 \mathrm{NaCl}+4.5 \mathrm{C}= \\
& 3 \mathrm{NaCN}+1.5 \mathrm{CaCl}_{2}+1.5 \mathrm{CaCN}_{2}+ \\
& 3 \mathrm{CaC}_{2}+2 \mathrm{CO}+\mathrm{N}_{2}
\end{aligned}
$$

or in more general terms:

$$
\begin{gathered}
2 \mathrm{CaO}+4 \mathrm{Ca}(\mathrm{CN})_{2}+3 \mathrm{NaCl}+(3.5+\mathrm{x}) \mathrm{C}= \\
3 \mathrm{NaCN}+1.5 \mathrm{CaCl}_{2}+(2.5-\mathrm{x}) \mathrm{CaCN}_{2}+ \\
(2+\mathrm{x}) \mathrm{CaC} \mathrm{Ca}_{2}+2 \mathrm{CO}+\mathrm{xN},
\end{gathered}
$$

As shown in Figure 8 , the standard free energy changes for reactions (13) and (15) are large and positive over the whole temperature range of interest. Thus the quenched product should consist mainly of the reactants and small amounts of the products. Assuming that the melt is mostly calcium cyanide, sodium chloride and lime, then the stoichiometric melt composition according to equation (14) and using $x=0.5$ is: $54.6 \%$ calcium cyanide, $28.8 \%$ sodium chloride and $16.6 \%$ lime. These values are in reasonable agreement with the normalized values for a typical industrial melt composition of $52.9 \%$ calcium cyanide, $34.4 \%$ sodium chloride and $12.7 \%$ lime. Assuming that the calcium cyanide all originated from calcium cyanamide then the original salt to cyanamide mass ratio of the charge according to equation (14) with $x=0.5$ is 0.61 , which is within the range of the industrial ratios. In typical "black cyanide", the mass ratio of unreacted cyanamide to calcium carbide is about 1.75 , while using $x=0.5$ in equation (14) gives a ratio of 1.46. These results indicate that the above equations provide a good

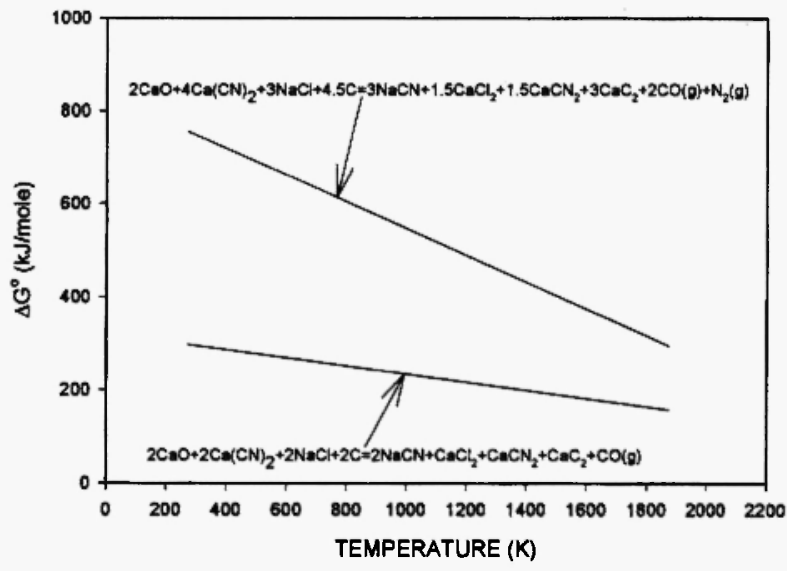

Fig. 8: Standard free energy changes for two equilibrium reactions utilized to describe the black cyanide process.

description of the reaction once equilibrium has been attained. If the amount of calcium carbide in the charge is below the equilibrium value, then reactions (13-16) will shift to the right and this will reduce the grade of the "black cyanide" product. On the other hand, calcium carbide additions to the charge improve the grade by ensuring that the equilibrium product distribution is maintained. Furthermore, Landis found that calcium carbide additions reduced foaming $/ 2 \%$. With higher calcium carbide additions to the charge, less calcium cyanamide will dissociate to produce calcium carbide and nitrogen. Additionally, with increased calcium carbide additions there will be limited reduction of lime and therefore less carbon monoxide reduced. Thus, calcium carbide additions reduce gas production which is the cause of foaming. These equations also indicate that, because of equilibrium considerations, some calcium cyanamide will be found in the product.

\section{CALCIUM CYANIDE FORMATION REACTION MECHANISM}

\section{Reaction Mechanism}

The formation of calcium cyanamide from calcium cyanide according to equation (3) requires the reaction of the calcium cyanamide with carbon and is facilitated by the presence of molten salt. Therefore it is likely that 
the actual formation of the cyanide ion occurs in the molten salt and the salt provides an ionic reaction medium. Since the cyanide formation reaction requires the availability of carbon in ionic form, in the melt, then calcium carbide could play a crucial role in the process by providing carbon ions. It has been shown previously that, in ionic melts of this type, the calcium carbide readily dissociates into the melt as the calcium ion $\left(\mathrm{Ca}^{2+}\right)$ and the acetylide ion $\left(\mathrm{C}_{2}{ }^{2-}\right) / 10 /$ as follows:

$$
\mathrm{CaC}_{2} \rightarrow \mathrm{Ca}^{2+}+\mathrm{C}_{2}^{2-}
$$

Also it would be expected that the calcium cyanamide would dissociate in the molten salt:

$$
2 \mathrm{CaCN}_{2} \rightarrow 2 \mathrm{Ca}^{2+}+2 \mathrm{CN}_{2}^{2}
$$

Then the cyanamide ion $\left(\mathrm{CN}_{2}{ }^{2-}\right)$ and the acetylide ion $\left(\mathrm{C}_{2}{ }^{2-}\right)$ would react in the molten salt to produce the cyanide ion $\left(2 \mathrm{CN}^{-}\right)$:

$$
2 \mathrm{CN}_{2}{ }^{2-}+\mathrm{C}_{2}{ }^{2-}=4 \mathrm{CN}^{-}+2 \mathrm{e}^{-}
$$

However, in order to balance the equation an excess of electrons $\left(2 \mathrm{e}^{-}\right)$is produced on the right hand side of equation (19). Another more realistic method of balancing the equation is as follows:

$$
\mathrm{Ca}^{2+}+2 \mathrm{CN}_{2}{ }^{2-}+\mathrm{C}_{2}{ }^{2-}=4 \mathrm{CN}^{-}+\mathrm{Ca}(\mathrm{g})
$$

The cyanide formation mechanism and the reactions involving calcium are illustrated in the schematic diagram in Figure 9. The calcium vapors produced as a result of reaction (20) above would oxidize and condense as they migrate upwards through the burden and then they would physically descend with the charge back down to the reduction zone. There the calcium oxide would be converted to calcium carbide and dissolve in the melt. The standard free energy change for the reduction of calcium oxide by carbon to produce calcium carbide as given by equation (1) is large and positive at the operating temperatures of the "black cyanide" process. However, the reduced activity of the calcium carbide in the melt and the low partial pressures of carbon monoxide could facilitate a limited amount of reaction. Figure 10 shows the standard free energy

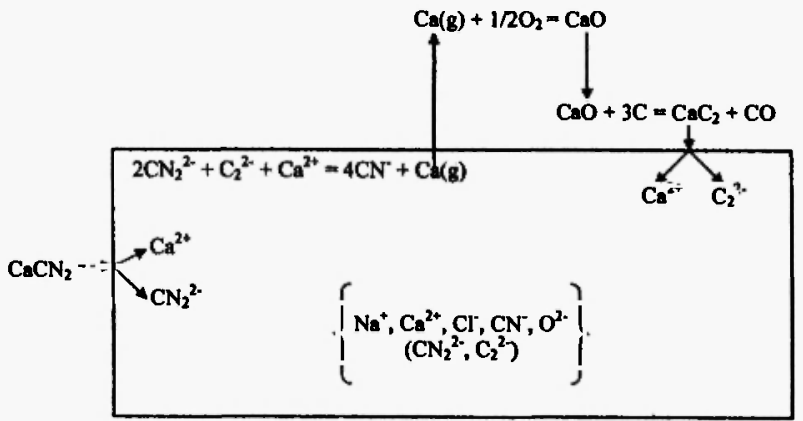

Fig. 9: Proposed reaction mechanism for the black cyanide process.

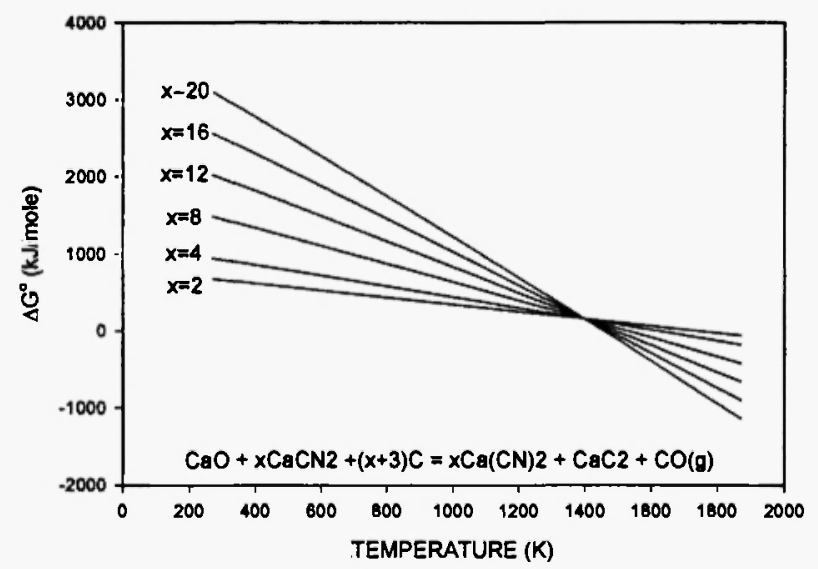

Fig. 10: Standard free energy changes for the reaction of calcium cyanamide, lime and carbon at various $\mathrm{x}$ values.

change for the reaction of lime, calcium cyanamide and carbon as given by the following reaction at various $x$ values in the range of 2 to 20 :

$$
\begin{aligned}
\mathrm{CaO} & +\mathrm{xaCN}_{2}+(\mathrm{x}+3) \mathrm{C}=\mathrm{xCa}(\mathrm{CN}) \\
& +\mathrm{CaC}_{2}+\mathrm{CO}(\mathrm{g})
\end{aligned}
$$

It can be seen from the Figure that the temperature at which the standard free energy change for the reaction becomes equal to zero decreases with increasing $x$ value. Also it can be seen that even with the species at unit activity and a partial pressure of carbon monoxide equal to one atmosphere, the reaction is feasible over the operating temperature range of the "black cyanide" process. The small amount of calcium carbide which is produced will dissolve in the melt and provide further 
acetylide ions $\left(\mathrm{C}_{2}{ }^{2-}\right)$ for the conversion of the cyanamide ion into the cyanide ion. This small recirculating load of calcium would be sufficient to ensure that there is a small amount of acetylide ions $\left(\mathrm{C}_{2}{ }^{2-}\right)$ at all times in the melt and an equilibrium process is established such that the rate of consumption of the acetylide ions is matched by the generation rate. Thus, if calcium carbide -were present in the initial furnace charge then this should facilitate the conversion reaction. In the actual process, it is important that the calcium cyanamide is rapidly converted into cyanide in order to avoid reversion of the cyanamide back to calcium carbide and nitrogen gas. Therefore, in addition to promoting the conversion reaction the presence of some calcium carbide both in the charge and in the melt would also minimize nitrogen gas evolution.

\section{ANALYSIS OF INDUSTRIAL CALCIUM CYANIDE PRODUCTION RESULTS}

\section{Effect of Moisture}

Figure 11 shows a plot of the efficiency of conversion of calcium cyanamide to calcium cyanide during the various months of the year over a two year period for an industrial operation for the manufacture of calcium cyanide. Although there is considerable scatter in the data, the data points were fitted to a third order regression analysis and it can be seen that there is a trend to lower conversion efficiencies during the late summer months and higher conversion efficiencies during the winter months. This trend may reflect the higher humidity levels during the summer, which results in the degradation of the raw material and also possibly the cyanide product itself.

In order to explain the results for the effect of moisture on the cyanide process, it is necessary to consider the reaction of the moisture with calcium cyanamide and lime, which are the two major components of the charge, as follows:

$$
\begin{aligned}
& \mathrm{CaCN}_{2}+3 \mathrm{H}_{2} \mathrm{O}_{(\mathrm{g})}=\mathrm{CaO}+2 \mathrm{NH}_{3(\mathrm{~g})}+\mathrm{CO}_{2(\mathrm{~g})} \\
& \mathrm{CaCN}_{2}+3 \mathrm{H}_{2} \mathrm{O}_{(\mathrm{g})}=\mathrm{CaCO}_{3}+2 \mathrm{NH}_{3(\mathrm{~g})} \\
& \mathrm{CaO}+\mathrm{H}_{2} \mathrm{O}_{(\mathrm{g})}=\mathrm{Ca}(\mathrm{OH})_{2}
\end{aligned}
$$

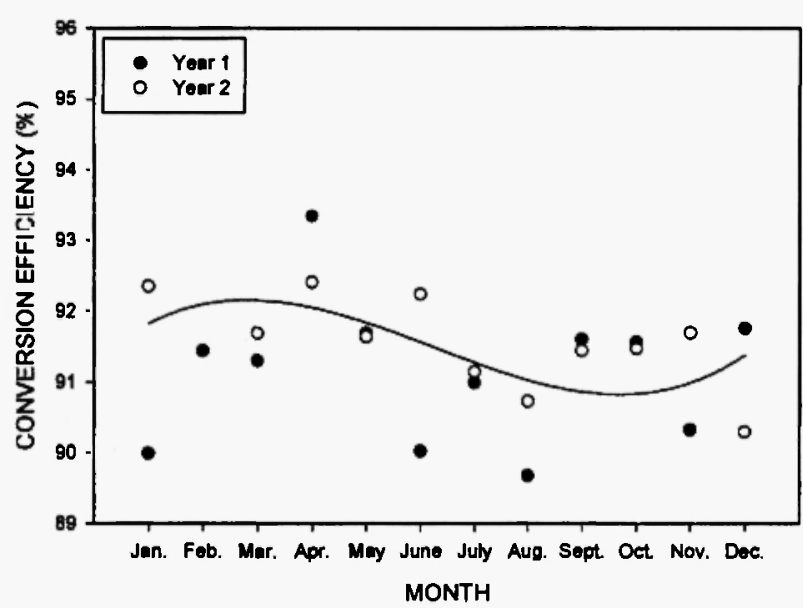

Fig. 11: Conversion efficiency over a period of two years for an industrial "black cyanide" operation.

Using the thermodynamic data for calcium cyanamide and calcium cyanide the various possible reaction scenarios can be analyzed thermodynamically and the results are illustrated in Figure 12. At temperatures below about $1300 \mathrm{~K}$, the standard free energy changes for reaction (22) and (23) are negative and thus high moisture contents in the furnace charge would result in decomposition of the calcium cyanamide. The reaction

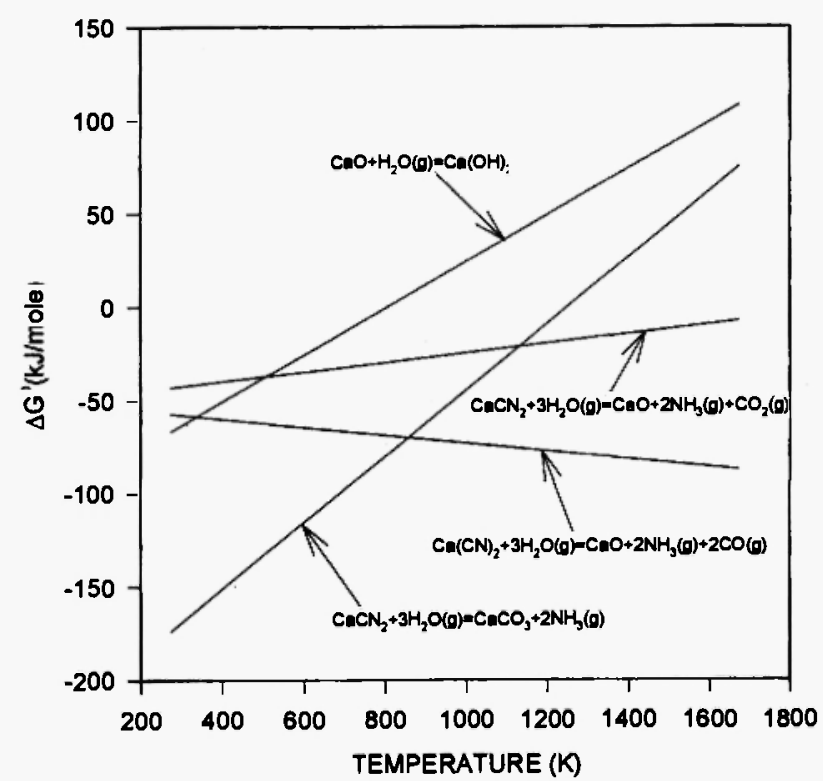

Fig. 12: Thermodynamic evaluation of the possible reactions of calcium cyanamide and calcium cyanide with moisture (6). 
of calcium cyanamide with moisture results in the conversion of some cyanamide into calcium oxide or calcium carbonate and thus the cyanide product grade will decrease. In addition, carbon dioxide can be evolved which can cause further oxidation of the charge as follows:

$$
\mathrm{CaCN}_{2}+2 \mathrm{CO}_{2(\mathrm{~g})}=\mathrm{CaO}+3 \mathrm{CO}_{(\mathrm{g})}+\mathrm{N}_{2(\mathrm{~g})}
$$

Any calcium hydroxide in the charge or any that is produced via reaction (24) will decompose in the cyanide furnace and release moisture which will further hydrolyze the cyanamide. Thus, the cyanide grade decreases because the cyanamide decomposes and nitrogen is lost from the system as ammonia and also the generation of the lime results in the dilution of the cyanide product. In addition, the authors have previously shown that the presence of moisture and the corresponding generation of excess lime can result in an increase in the viscosity of the melt $/ 6 /$. Since it is necessary to rapidly quench the liquid cyanide in order to avoid reversion, then an increase in melt viscosity can result in inefficient quenching and a decrease in the cyanide grade. Furthermore, both moisture and carbon dioxide can degrade the actual cyanide product as follows:

$$
\begin{aligned}
& \mathrm{Ca}(\mathrm{CN})_{2}+3 \mathrm{H}_{2} \mathrm{O}_{(\mathrm{g})}=\mathrm{CaO}+2 \mathrm{NH}_{3(\mathrm{~g})}+2 \mathrm{CO}_{(\mathrm{g})} \\
& \mathrm{Ca}(\mathrm{CN})_{2}+\mathrm{CO}_{2(\mathrm{~g})}=\mathrm{CaCN}_{2}+2 \mathrm{CO}_{(\mathrm{g})}
\end{aligned}
$$

\section{Effect of Salt to Cyanamide Ratio}

Figure 13 shows the effect of the salt to cyanamide ratio of the charge on both the equivalent sodium cyanide content of the "black cyanide" product and the conversion efficiency. It is clear from these industrial results that increasing the salt to cyanamide ratio of the feed improves the conversion efficiency and also increases the grade of the product. The effect on the conversion efficiency is more significant. Increasing salt additions would dilute the melt and therefore reduce the equivalent sodium cyanide content. From a thermodynamic perspective, as shown in Figure 4, Figure 6 and Figure 7, an increasing salt to cyanamide

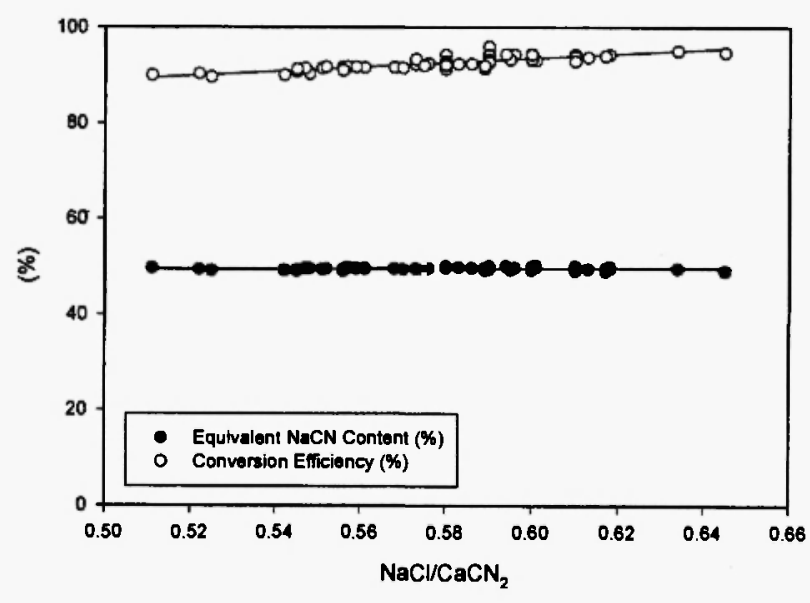

Fig. 13: Conversion efficiency and equivalent sodium cyanide content as a function of the salt to cyanamide ratio for an industrial "black cyanide" operation.

ratio would increase the temperature required for the formation of calcium cyanide and thus an increasing ratio would be expected to hinder the conversion of calcium cyanamide to calcium cyanide. This apparent contradiction between the thermodynamic calculations and the industrial observations would tend to support the hypothesis that the major role of the salt is to act as an ionic reaction medium. An increased amount of salt in the feed would provide an increased surface area for reaction which would facilitate the dissolution and the reaction of the various species. Decomposition of the cyanamide would be reduced. Therefore the conversion efficiency would be improved and the dilution effect of the additional salt would be compensated for by the improvement in the grade.

\section{Effect of Calcium Carbide Additions}

In industrial operations it has been found that calcium carbide additions have an effect on both the grade of the "black cyanide" and the conversion efficiency of calcium cyanamide to calcium cyanide. Figure 14 shows the effect of the calcium carbide content of the feed on the calcium carbide content of the product and Figure 15 shows the relationship between the calcium carbide content of the product and the cyanamide conversion efficiency. As is illustrated in the 


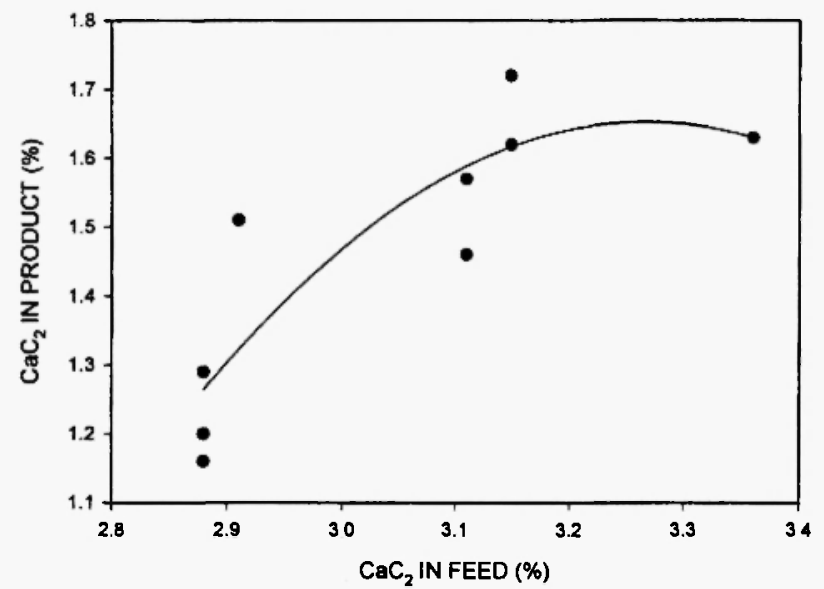

Fig. 14: Calcium carbide content of the product as a function of the calcium carbide content of the feed for an industrial "black cyanide" operation.

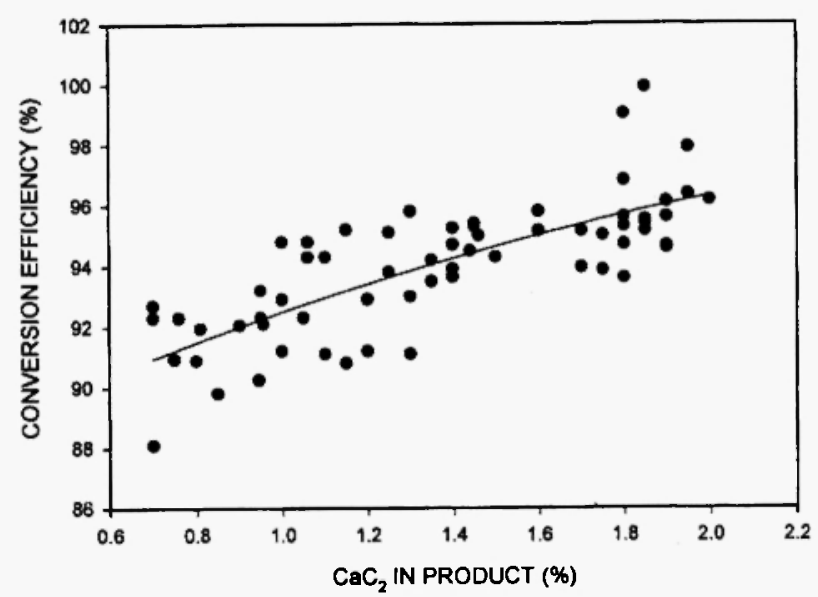

Fig. 15: Conversion efficiency as a function of the calcium carbide content of the product for an industrial "black cyanide" operation.

two Figures, an increasing amount of calcium carbide in the feed results in higher calcium carbide contents of the product and an enhanced calcium cyanamide conversion efficiency. Also Figure 14 demonstrates that as the calcium carbide content of the feed increases, the calcium carbide content of the product levels off in the range of 1.6 to $1.8 \%$. Similarly, the conversion efficiency begins to level off at similar calcium carbide contents of the product in Figure 15. These results indicate that there is an equilibrium calcium carbide content of the product of about $2 \%$. As discussed previously, the salt acts as an ionic reaction medium and the calcium carbide is the source of the carbon ions $\left(\mathrm{C}_{2}{ }^{2-}\right)$ required for the conversion of calcium cyanamide into calcium cyanide. Although it is likely that some calcium carbide can be generated in the cyanide production process itself, according to the mechanism discussed previously, the thermodynamic feasibility of this reaction is limited. Therefore, the addition of increased amounts of calcium carbide in the charge would be expected to promote the reaction. However, since the equilibrium calcium carbide content of the product is about $2 \%$, then additions beyond those required to achieve the maximum conversion would have a diminishing effect.

\section{CALCIUM CYANAMIDE AND CYANIDE AND DIAMOND FORMATION}

It has been proposed that the cyanamides of both magnesium and calcium could act as melt mineralizers and play a role in the natural process of diamond formation /4,5/. The reversible reaction as shown by equation (3) can account for both carbon dissolution and also diamond precipitation. Figure 16(a) and (b) show the predominance area diagrams for the Ca-C-N system, which were calculated for the two cases where the carbon is present as graphite and diamond, respectively. For graphite, the equilibrium line between calcium cyanamide and calcium cyanide occurs at a carbon activity of unity when the temperature is $1395 \mathrm{~K}$. For diamond, the same conditions are met when the temperature is $1335 \mathrm{~K}$.

In the kimberlite pipes, methane could provide a source of carbon for cyanide production according to the following equation:

$$
\mathrm{CaCN}_{2}+\mathrm{CH}_{4}=\mathrm{Ca}(\mathrm{CN})_{2}+2 \mathrm{H}_{2}
$$

As shown in Figure 17, at one atmosphere total pressure, this reaction becomes thermodynamically possible at temperatures above $1130 \mathrm{~K}$. Diamond crystallization results from the decomposition of the calcium cyanide to calcium cyanamide and carbon as 


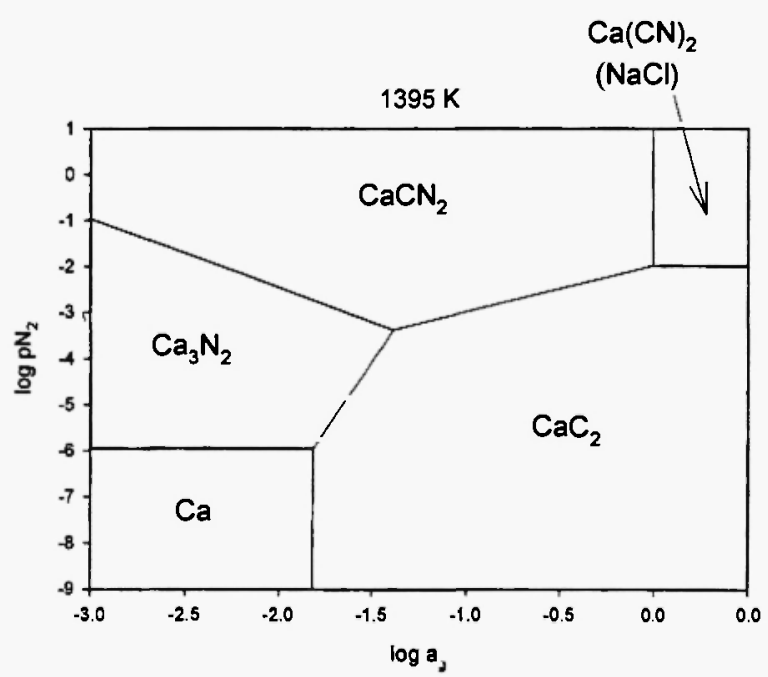

(a)

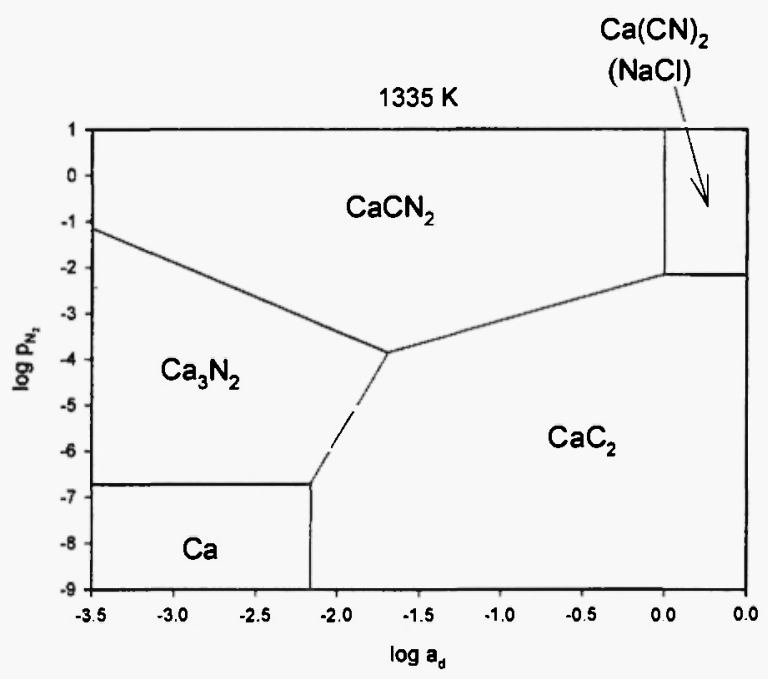

(b)

Fig. 16: Predominance area diagrams for the calciumcarbon-nitrogen system for: (a) carbon in the form of graphite at $1395 \mathrm{~K}$ and (b) carbon in the form of diamond at $1335 \mathrm{~K}$.

follows:

$$
\mathrm{Ca}(\mathrm{CN})_{2}=\mathrm{CaCN}_{2}+\mathrm{C}_{(\mathrm{d})}
$$

This reaction would become feasible at temperatures below about $1335 \mathrm{~K}$. The addition of reactions (28) and (29) gives the overall reaction;

$$
\mathrm{CH}_{1}=2 \mathrm{H}_{2}+\mathrm{C}_{(\mathrm{d})}
$$

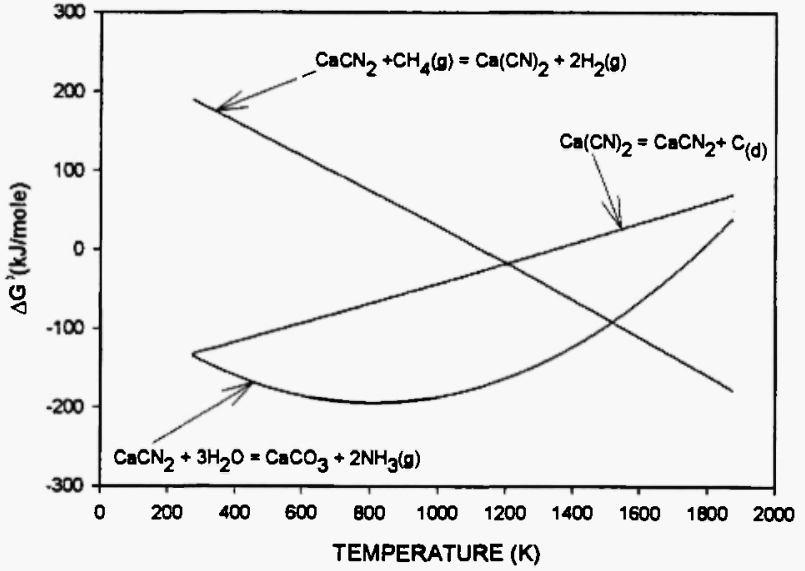

Fig. 17: Thermodynamic evaluation of possible reactions in diamond formation involving calcium cyanamide and calcium cyanide.

Methane, hydrogen and diamond would be in equilibrium at the intersection of the two lines corresponding to reactions (28) and (29). The temperature of intersection is $1204 \mathrm{~K}$ and below this temperature diamond formation would be favored. Subsequently after diamond formation, the calcium cyanamide reacts with water and is converted to calcium carbonate as follows:

$$
\mathrm{CaCN}_{2}+3 \mathrm{H}_{2} \mathrm{O}=\mathrm{CaCO}_{3}+2 \mathrm{NH}_{3}
$$

As shown in Figure 17, this reaction is thermodynamically favorable from room temperature to $1780 \mathrm{~K}$. In this way, the cyanamide is removed from the kimberlite pipe as calcium carbonate. Thus, this thermodynamic analysis indicates that both calcium cyanamide and calcium cyanide could play a role in the process of natural diamond formation.

\section{CONCLUSIONS}

The thermodynamic data available for the formation of calcium cyanide in a molten salt solution was employed to develop predominance area diagrams for the calcium-carbon-nitrogen system. These diagrams can be utilized to predict the stability ranges of the various species in the calcium-carbon-nitrogen system 
and also to delineate possible reaction paths for the production of compounds such as calcium cyanamide and calcium cyanide. Also, a series of possible reactions and a reaction mechanism were developed in order to gain an improved understanding of the conversion of calcium cyanamide to calcium cyanide in the commercial "black cyanide" production process. This thermodynamic analysis indicates that sodium chloride, calcium carbide and lime, which are present in the process, as either additions or impurities, play critical roles in the conversion reaction. The molten salt provides an ionic reaction medium in which the calcium carbide can dissolve and generate carbon ions which are required for the production of the cyanide ion from the cyanamide ion. The regeneration of the calcium carbide is achieved by the reduction of a small amount of lime. The thermodynamic information and the proposed reaction mechanism are utilized to further elucidate the effects of moisture, calcium carbide additions and the salt to cyanamide ratio on the conversion efficiency and the product grade in the commercial production process. Additionally, some comments are made on the possible roles of calcium cyanamide and calcium cyanide as intermediate species in the formation of natural diamonds in kimberlite pipes.

\section{ACKNOWLEDGEMENTS}

The authors would like to thank Cyanamid Canada Inc., for not only the financial support for this research but also for the many useful discussions during the course of this study. C. A Pickles would like to thank Professor J. M. Toguri for providing him with the opportunities to participate in a number of projects and for stimulating his interest in various subjects, including the one discussed in the present paper.

\section{REFERENCES}

1. W. S. Landis, "Canadian cyanide, its manufacture and utilization", Can. Chem. J., 4, 130-132 (1920).

2. W. S. Landis, "A new cyanide", Chem. Met. Eng., 22, 265-268 (1920).

3. W. S. Landis, United States Patent No. 1359257 , Nov. 16, 1920.

4. G. B. Bokii, A. V. Nikitin and S. V. Pepin, "Chemical transport of carbon by nitrogencontaining "intermediate compounds" as a feature of the mechanism of synthesis of natural diamonds", Doklady Akademii Nauk SSSR, 266 (3), $711-714$ (1982).

5. A. V. Nikitin, "Effect of some nitrogen-containing compounds on the synthesis and mechanism of the crystallization of diamonds from a solution in a melt", Izvestiya Vysshikh Uchebnykh Zavedenii, Khimiya i Khimicheskaya Tekhnologiya, 23 (8), 994-998 (1980).

6. C. A. Pickles, J. M. Toguri, and R. A. Bergman, "A physiochemical study of the "black cyanide" process", Can. Met. Quart, 41 (3), 299-308 (2002).

7. V. B. Parker, D. W. Wagman and W. H. Evans, Selected Values of Chemical Thermodynamic Properties, Tables for the Alkaline Earth Elements, NBS Technical Note 270-6, Nov. 1971, p. 47.

8. I. Barin, Thermochemical Data of Pure Substances, Part $l \mathrm{Ag}-\mathrm{Kr}, 2^{\text {id }}$ ed. $\mathrm{VCH}$ Verlagsgesellschaft $\mathrm{mbH}$, Federal Republic of Germany, 1993, p. 287.

9. G. Petersen and H. H. Franck, "A study of calcium cyanide, especially the transformation calcium cyanide = calcium cyanamide", Z. Anorg. $U_{\text {. }}$ Allgem. Chem., 237, 11-37 (1938).

10. J. F. Maillot and D. R. Morris, "Phase relations in the calcium chloride-calcium carbide system", Canadian Journal of Chemistry, 50 (6), 839-843 (1972). 